\title{
Aquecimento de vinho tinto e suco de uva utilizados em preparações culinárias não afeta a capacidade antioxidante e o teor de fenóis totais
}

\section{$\int\left(\int_{0}\right.$}

Heating of red wine and grape juice in food preparations

does not affect their antioxidant capacity

and total phenol content

Jeanine Schütz Cardoso TEÓFILO'

Greyce Luci BERNARDO'

Edson Luiz da SILVA ${ }^{1}$

Rossana Pacheco da Costa PROENÇA ${ }^{1}$

RE S U M O

\section{Objetivo}

Avaliar a capacidade antioxidante e a concentração dos compostos fenólicos de vinho tinto e suco de uva utilizados em preparações culinárias, quando submetidos ao processo de fervura.

\section{Métodos}

A avaliação ocorreu após diferentes períodos de aquecimento $\left(100^{\circ} \mathrm{C}\right)$ em dois sistemas: i) panela de alumínio e chama de fogão e ii) balão de vidro e manta térmica. Amostras comerciais de vinho tinto $(n=4)$ e suco de uva integral $(n=4)$ foram submetidas à fervura por 10, 20 e 60 minutos. Antes e após cada período de fervura, a capacidade antioxidante total foi avaliada pela medida do potencial redutor férrico, e o teor de fenóis totais foi quantificado pelo método de Folin-Ciocalteau. As diferenças foram comparadas pela análise de variância para medidas repetidas $(p<0,05)$.

\section{Resultados}

A fervura durante os diferentes períodos de tempo não provocou variações importantes na capacidade antioxidante total e no teor de fenóis totais das bebidas, independentemente do sistema de aquecimento utilizado.

\footnotetext{
1 Universidade Federal de Santa Catarina, Centro de Ciências da Saúde, Programa de Pós-Graduação em Nutrição, Núcleo de Pesquisa de Nutrição em Produção de Refeições. Campus Universitário, Trindade, 88040-900, Florianópolis, SC, Brasil. Correspondência para/Correspondence to: R.P.C. PROENÇA. E-mail: <rossana@mboxl.ufsc.br>.

Apoio: Conselho Nacional de Desenvolvimento Científico e Tecnológico, Edital Universal 2004, projeto 470613/2004-1 e Bolsas de Iniciação Científica.
} 
154 | J.S.C. TEÓFILO et al.

\section{Conclusão}

De acordo com os resultados obtidos, as propriedades antioxidantes do vinho tinto e do suco de uva, quando submetidos à fervura por até 60 minutos, mantiveram-se relativamente estáveis.

Termos de indexação: Antioxidante. Estabilidade térmica. Fenóis. Gastronomia. Nutrição. Suco de uva. Vinho.

\section{A B S T R A C T}

\section{Objective}

This study evaluated the antioxidant capacity and concentration of phenolic compounds in red wine and grape juice used in culinary preparations subjected to boiling.

\section{Methods}

The assessments were done after different boiling times $\left(100^{\circ} \mathrm{C}\right)$ using two systems: i) aluminum pot and stove flame and ii) volumetric flask and heating mantle. Samples of red wine $(n=4)$ and grape juice $(n=4)$ were subjected to boiling for 10, 20 and 60 minutes. Before and after each boiling period, the total antioxidant capacity was evaluated by the ferric reducing antioxidant power assay and the total phenol content was determined by the Folin-Ciocalteu reagent. Differences were compared by repeated measures analysis of variance (RM-ANOVA) ( $p<0.05)$.

\section{Results}

The different boiling times did not cause significant changes in the total antioxidant capacity or total phenol content of the beverages, regardless of boiling method.

\section{Conclusion}

The results show that the antioxidant properties of red wine and grape juice did not change significantly after boiling for 60 minutes.

Indexing terms: Antioxidant. Thermal stability. Phenols. Gastronomy. Nutrition. Grape juice. Red wine.

\section{N T R O D U ÇÃ O}

Os compostos fenólicos encontram-se distribuídos no reino vegetal, especialmente nas frutas, verduras e bebidas como chá, café, cacau, cerveja, vinho e sucos ${ }^{1}$. A uva é uma das maiores fontes de compostos fenólicos, sendo os principais os flavonóides (antocianinas, flavanóis e flavonóis), os estilbenos (resveratrol), os ácidos fenólicos (derivados dos ácidos cinâmicos e benzóicos) e ampla variedade de taninos ${ }^{2}$.

Os compostos fenólicos da uva agem como protetores nutricionais, atuando na prevenção de desordens crônicas ${ }^{3}$. Da mesma forma, o vinho tinto e o suco de uva são bebidas reconhecidas como benéficas à saúde humana devido à presença de compostos fenólicos. Essas substâncias podem proteger os indivíduos contra várias desordens metabólicas devido ao seu efeito antioxidante, conforme relatado em estudos in vitro e em animais ${ }^{4,5}$.
O suco de uva e o vinho tinto estão presentes, com frequência, em receitas da culinária nacional e internacional, adotadas por muitas Unidades Produtoras de Refeições (UPR). Analisando a história da alimentação, a utilização de vinho em receitas culinárias é relatada em diferentes épocas ${ }^{6}$ e, já no século XVIII, Jean-Anthelme Brillat-Savarin, considerado o escritor precursor da gastronomia francesa, exaltava as propriedades do vinho no fazer culinário ${ }^{7}$. Desde a instalação da cozinha portuguesa no Brasil, já se ouvia falar do uso do vinho nas preparações culinárias. A mistura do alho com vinho, denominada vinha-d'alhos, era a salmoura aplicada à carne de porco. Daí o ditado popular: "onde alhos há, vinhos haverá"8.

As principais preparações em que se empregam essas bebidas, atualmente no Brasil, são os molhos para carnes (molho madeira) e as sobremesas (sagu de vinho ou suco de uva). Segundo 
Novakoski \& Freire ${ }^{9}$, o vinho tinto é uma bebida versátil que pode ser utilizado para marinar carnes, peixes e aves; deglaçar (incorporar o líquido e diluir os sucos concentrados na panela em que acabou de ser cozida, frita ou assada a carne ${ }^{10}$ ) panelas ou frigideiras; servir como líquido de cozimento para o pochê e ainda aromatizar frutas e molhos de sobremesas. De acordo com Montebello ${ }^{11}$, a utilização do vinho tinto na condimentação de carnes, por meio de marinadas, dá-se devido à ação amaciadora e por conferir sabor. Há várias formas de marinadas indicadas para certos tipos de carne, sendo as mais comuns as que empregam alecrim, alho, cebola, coentro, vinagre, vinho tinto ou branco e diversos condimentos. Os molhos, por sua vez, são preparações líquidas que realçam os sabores e melhoram a aparência do prato. Dentre os molhos clássicos da cozinha francesa, destacam-se o Bigarade, em que se utilizam vinho do Porto, suco e cascas de laranja e limão; o Bordelaise, com vinho tinto, cebola picada, grãos de pimenta-do-reino, louro, suco de limão; e o Financière, com vinho Madeira, essência de trufas e Marchand de vin, com cebola roxa e vinho tinto.

Na maioria das técnicas de preparo culinário, o vinho tinto ou suco de uva são submetidos a altas temperaturas. Por esse motivo, o tempo e a temperatura de aquecimento durante o processo culinário merecem atenção quando se analisa a qualidade nutricional da preparação. Porém, poucos estudos têm explorado essa questão. As pesquisas que vêm sendo feitas estão relacionadas ao uso de marinadas de vinho para temperar carnes e, assim, aproveitar o poder antioxidante dessa bebida. Marinar com vinho tinto é uma prática culinária muito utilizada em vários países, e serve para minimizar a formação de Aminas Heterocíclicas $(\mathrm{AH})$, potencialmente carcinogênicas, em frangos fritos ${ }^{12}$. Melo et al. ${ }^{13}$ também observaram a redução na formação de AHs em bifes fritos, marinados previamente por até seis horas no vinho tinto. No entanto, não foram encontrados na literatura, até o momento, estudos sobre a atividade antioxidante do vinho tinto e/ou do suco de uva submetidos ao processo de fervura a $100^{\circ} \mathrm{C}$.
Vale destacar que o conhecimento sobre a possível degradação dos compostos fenólicos do vinho tinto ou do suco de uva pela cocção poderá fornecer subsídios para ações que melhorem a qualidade nutricional e sensorial de preparações contendo estas bebidas. Dessa forma, o objetivo do presente estudo foi avaliar a atividade antioxidante e a estabilidade térmica dos compostos fenólicos totais do vinho tinto e do suco de uva submetidos ao processo de fervura.

\section{MÉ TODOS}

Para a realização do estudo foram utilizados produtos comerciais de uso corrente em UPR, constituídos de amostras de vinho tinto $(n=4)$ e suco de uva $(n=4)$, sendo cada bebida da mesma marca e lote. As amostras foram submetidas à fervura $\left(100^{\circ} \mathrm{C}\right)$ por até 60 minutos, em dois procedimentos: i) $500 \mathrm{~mL}$ em panela de alumínio e chama de fogão (para simular a utilização culinária das bebidas) e ii) $150 \mathrm{~mL}$ em balão de vidro, manta térmica e coluna de refluxo.

Alíquotas de $2 \mathrm{~mL}$ do vinho ou do suco foram retiradas, em duplicata, dos sistemas de aquecimento antes e após 10, 20 ou 60 minutos de fervura para a quantificação da capacidade antioxidante total e do teor de fenóis totais. O volume total das amostras de vinho e de suco de uva nos sistemas de aquecimento foi medido em proveta antes e após cada período de fervura, e o volume evaporado (5\% a 10\%) foi reposto com água destilada para minimizar as variações nas medidas dos constituintes devidas à concentração das amostras. A temperatura das bebidas durante os períodos de aquecimento foi medida com termômetro digital do tipo espeto, marca Incoterm escala $-50^{\circ} \mathrm{C} \mathrm{a}+300^{\circ} \mathrm{C}$.

A medida da capacidade antioxidante total das amostras de vinho tinto e de suco de uva foi realizada com base no método FRAP (do inglês, ferric reducing antioxidant power), descrito originalmente por Benzie \& Strain ${ }^{14}$ e modificado por Tsao et al. ${ }^{15}$. Esse método se baseia no potencial antioxidante redutor férrico de compostos antioxi- 
dantes presentes nas amostras. Neste ensaio, os antioxidantes atuam como redutores do ín férrico $\left(\mathrm{Fe}^{+3}\right)$ ao íon ferroso $\left(\mathrm{Fe}^{+2}\right)$, o qual é quelado pela 2,4,6-Tri(2-piridil)-s-triazina (TPTZ) para formar o complexo Fe+2-TPTZ, com absorção máxima em 593nm. Resumidamente, $10 \mu \mathrm{L}$ das bebidas (diluídas 50 vezes em água) foram adicionados a 1,0mL da solução de trabalho, a qual foi preparada misturando-se tampão acetato de sódio $(300 \mathrm{mM}, \mathrm{pH} 3,6)$, TPTZ $(10 \mathrm{mM})$ em $\mathrm{HCl}$ $(40 \mathrm{mM})$ e cloreto férrico $\left(\mathrm{FeCl}_{3} ; 20 \mathrm{mM}\right)$ na proporção de 10:1:1 (v/v/v). A mistura foi incubada por 15 minutos a $37^{\circ} \mathrm{C}$ e, posteriormente, realizou-se a leitura da absorbância do produto colorido em 593nm (espectrofotômetro Spectrum SP2000). A capacidade antioxidante total foi calculada a partir da curva-padrão de Trolox $(50-800 \mu \mathrm{M})$, análogo hidrossolúvel da vitamina $\mathrm{E}$. A equação obtida com o Trolox foi $y=0,0004302 x-0,00297$. Os resultados foram expressos em mmol equiv. Trolox/L das bebidas.

O teor de fenóis totais nas amostras de vinho tinto e de suco de uva foi determinado pelo método colorimétrico de Folin-Ciocalteau, segundo Singleton et al. ${ }^{16}$, com algumas modificações. Cinquenta microlitros das bebidas (diluídas 10 vezes em água) foram misturados com $150 \mu \mathrm{L}$ de etanol (95\%), 800 $\mu \mathrm{L}$ de água destilada e $80 \mu \mathrm{L}$ do reagente de Folin-Ciocalteau (50\%). Após 5 minutos, foram adicionados $150 \mu \mathrm{L}$ de bicarbonato de sódio $(5 \mathrm{~g} / 100 \mathrm{~mL})$, e a mistura permaneceu à temperatura ambiente por 1 hora, na ausência de luz. A leitura da absorbância do produto colorido foi realizada em comprimento de onda de 765 nm (espectrofotômetro Spectrum SP2000). O ácido gálico foi usado para preparar a curva-padrão (10,0 a 150,0 $\mu \mathrm{g} / \mathrm{mL})$ e o teor de fenóis totais foi calculado por meio da equação $y=0,0265 x+0,0007009$. Os resultados foram expressos em $\mathrm{mg}$ equiv. ácido gálico/mL das bebidas.

Os resultados foram expressos como Média (M), Desvio-Padrão (DP). As diferenças na capacidade antioxidante e no teor de fenóis totais das amostras de vinho tinto e suco de uva antes e após os diferentes períodos de aquecimento foram comparadas pela Análise de Variância
(ANOVA) para medidas repetidas, considerando $p<0,05$ como significativo ${ }^{17}$. O programa Statistical Package for Social Science (SPSS), versão 12,0, foi usado em todas as análises.

\section{RESULTADOS}

Inicialmente, o efeito da fervura na capacidade antioxidante total das bebidas foi avaliado em condições semelhantes aos processos usados em UPR, ou seja, utilizando-se panela de alumínio e chama de fogão. Pela avaliação dos resultados, observou-se que a capacidade antioxidante do vinho tinto permaneceu inalterada durante todo o período de tempo de fervura estudado. A capacidade antioxidante do suco de uva também apresentou variação não significativa de 4,6\%, 10\% e 4\% após 10, 20 e 60min de fervura, respectivamente (Tabela 1).

Na tentativa de confirmar os resultados observados com o aquecimento em panela e chama de fogão, ensaios adicionais foram realizados em laboratório, em sistema fechado de aquecimento, composto por balão de vidro, manta térmica e coluna de refluxo. Nesse sistema, também não foram constatadas variações significativas ou importantes na capacidade antioxidante do vinho tinto ou do suco de uva após 10, 20 ou 60min de fervura (Tabela 2). Com base nesses resultados, pode-se inferir que a diminuição em $10 \%$ na capacidade antioxidante do suco de uva verificada após 20 minutos de fervura em panela e chama de fogão pode ter sido decorrente de variação aleatória e, portanto, sem implicação prática.

É interessante notar que os fenóis presentes no vinho tinto sofreram degradação em torno de $8 \%$ após 10 minutos de fervura em panela e chama de fogão, porém se mantiveram estáveis com o prolongamento do tempo de fervura por 20 e 60 minutos, apresentando degradação não significativa de, em média, $5 \%$ (Tabela 3). No sistema de aquecimento com balão de vidro e manta térmica, os fenóis totais do vinho tinto também foram degradados em aproximadamente 5\% (Tabela 4). Ao contrário, os compostos fenólicos do suco de uva se mantiveram extre- 
Tabela 1. Capacidade antioxidante total de vinho tinto e suco de uva antes e após fervura em panela de alumínio e chama de fogão. Florianópolis (SC), 2008

\begin{tabular}{|c|c|c|c|c|c|c|c|}
\hline \multirow{3}{*}{ Tempo de aquecimento } & \multirow{3}{*}{ Capacidade antioxidante total (FRAP) } & \multicolumn{3}{|c|}{ Vinho tinto } & \multicolumn{3}{|c|}{ Suco de uva } \\
\hline & & \multicolumn{2}{|c|}{$\begin{array}{c}\mathrm{mmol} / \mathrm{L} \\
\text { (Eq. Trolox) }\end{array}$} & \multirow[t]{2}{*}{$\begin{array}{c}\text { Variação } \\
\text { (\% do controle) }\end{array}$} & \multicolumn{2}{|c|}{$\begin{array}{c}\mathrm{mmol} / \mathrm{L} \\
\text { (Eq. Trolox) }\end{array}$} & \multirow[t]{2}{*}{$\begin{array}{c}\text { Variação } \\
\text { (\% do controle) }\end{array}$} \\
\hline & & M & DP & & M & DP & \\
\hline Antes (controle) & & 19,21 & 1,06 & - & 21,13 & 4,65 & - \\
\hline Após 10 minutos & & 18,03 & 0,48 & $-4,70$ & 20,16 & 3,73 & $-4,60$ \\
\hline Após 20 minutos & & 19,00 & 1,73 & $-1,10$ & 18,89 & 4,19 & $-10,60$ \\
\hline Após 60 minutos & & 19,21 & 0,93 & 0,00 & 20,28 & 5,38 & $-4,00$ \\
\hline
\end{tabular}

FRAP, ferric reducing antioxidant power; M: media; DP: desvio-padrão.

Tabela 2. Capacidade antioxidante total de vinho tinto e suco de uva antes e após fervura em balão de vidro, manta térmica e coluna de refluxo. Florianópolis (SC), 2008.

\begin{tabular}{|c|c|c|c|c|c|c|c|}
\hline \multirow{3}{*}{ Tempo de aquecimento } & \multirow[t]{3}{*}{ Capacidade antioxidante total (FRAP) } & \multicolumn{3}{|c|}{ Vinho tinto } & \multicolumn{3}{|c|}{ Suco de uva } \\
\hline & & \multicolumn{2}{|c|}{$\begin{array}{c}\mathrm{mmol} / \mathrm{L} \\
\text { (Eq. Trolox) }\end{array}$} & \multirow[t]{2}{*}{$\begin{array}{c}\text { Variação } \\
\text { (\% do controle) }\end{array}$} & \multicolumn{2}{|c|}{$\begin{array}{c}\mathrm{mmol} / \mathrm{L} \\
\text { (Eq. Trolox) }\end{array}$} & \multirow[t]{2}{*}{$\begin{array}{c}\text { Variação } \\
\text { (\% do controle) }\end{array}$} \\
\hline & & M & DP & & M & DP & \\
\hline Antes (controle) & & 20,33 & 2,83 & - & 20,04 & 5,16 & - \\
\hline Após 10 minutos & & 20,24 & 1,63 & $-0,44$ & 19,70 & 4,86 & $-1,70$ \\
\hline Após 20 minutos & & 19,87 & 2,44 & $-2,26$ & 19,42 & 5,21 & $-3,09$ \\
\hline Após 60 minutos & & 19,54 & 3,52 & 3,88 & 20,75 & 7,86 & $-3,54$ \\
\hline
\end{tabular}

FRAP, ferric reducing antioxidant power; M: media; DP: desvio-padrão.

Tabela 3. Concentração de fenóis totais no vinho tinto e no suco de uva antes e após fervura em panela de alumínio e chama de fogão. Florianópolis (SC), 2008

\begin{tabular}{|c|c|c|c|c|c|c|}
\hline \multirow[t]{3}{*}{ Concentração de fenóis totais } & \multicolumn{3}{|c|}{ Vinho tinto } & \multicolumn{3}{|c|}{ Suco de uva } \\
\hline & \multicolumn{2}{|c|}{$\begin{array}{c}\text { Fenóis totais (mg Eq. } \\
\text { ácido gálico/mL) }\end{array}$} & \multirow[t]{2}{*}{$\begin{array}{c}\text { Variação } \\
\text { (\% do controle) }\end{array}$} & \multicolumn{2}{|c|}{$\begin{array}{c}\text { Fenóis totais (mg Eq. } \\
\text { ácido gálico/mL) }\end{array}$} & \multirow[t]{2}{*}{$\begin{array}{c}\text { Variação } \\
\text { (\% do controle) }\end{array}$} \\
\hline & $\mathrm{M}$ & DP & & M & DP & \\
\hline Antes (controle) & 0,87 & 0,09 & - & 1,03 & 0,14 & - \\
\hline Após 10 minutos & 0,78 & 0,08 & $-7,70$ & 0,96 & 0,16 & $-1,30$ \\
\hline Após 20 minutos & 0,79 & 0,04 & $-5,50$ & 0,99 & 0,17 & $-0,05$ \\
\hline Após 60 minutos & 0,82 & 0,07 & $-4,50$ & 0,96 & 0,16 & $-4,50$ \\
\hline
\end{tabular}

M: media; DP: desvio-padrão.

Tabela 4. Concentração de fenóis totais no vinho tinto e no suco de uva antes e após fervura em balão de vidro, manta térmica e coluna de refluxo. Florianópolis (SC), 2008.

\begin{tabular}{|c|c|c|c|c|c|c|}
\hline \multirow{3}{*}{ Tempo de aquecimento } & \multicolumn{3}{|c|}{ Vinho tinto } & \multicolumn{3}{|c|}{ Suco de uva } \\
\hline & \multicolumn{2}{|c|}{$\begin{array}{c}\text { Fenóis totais (mg Eq. } \\
\text { ácido gálico/mL) }\end{array}$} & \multirow[t]{2}{*}{$\begin{array}{c}\text { Variação } \\
\text { (\% do controle) }\end{array}$} & \multicolumn{2}{|c|}{$\begin{array}{c}\text { Fenóis totais (mg Eq. } \\
\text { ácido gálico/mL) }\end{array}$} & \multirow[t]{2}{*}{$\begin{array}{c}\text { Variação } \\
\text { (\% do controle) }\end{array}$} \\
\hline & M & DP & & M & DP & \\
\hline Antes (controle) & 0,88 & 0,15 & - & 0,93 & 0,17 & - \\
\hline Após 10 minutos & 0,82 & 0,21 & $-6,39$ & 0,94 & 0,16 & 0,55 \\
\hline Após 20 minutos & 0,83 & 0,16 & $-5,23$ & 0,95 & 0,17 & 2,00 \\
\hline Após 60 minutos & 0,83 & 0,17 & $-4,84$ & 0,95 & 0,22 & 1,46 \\
\hline
\end{tabular}

M: media; DP: desvio-padrão. 
mamente estáveis durante os diferentes períodos de tempo de fervura em panela e chama de fogão (Tabela 3) ou no sistema em balão de vidro, manta térmica e coluna de refluxo (Tabela 4).

\section{I S C U S S Ã O}

Em geral, de acordo com os resultados obtidos, a capacidade antioxidante total parece não estar associada ao teor de fenóis totais do vinho tinto e do suco de uva após o aquecimento. No entanto, merece destaque o fato de as amostras de vinho tinto e suco de uva continuarem a apresentar elevada atividade antioxidante, inclusive após o processo de aquecimento agressivo e por tempo prolongado (60 minutos) ao qual as bebidas foram submetidas. As variações observadas nos resultados da capacidade antioxidante e do teor de fenóis totais após os processos de fervura não foram estaticamente significativas, sempre estiveram abaixo de $10 \%$ e não foram dependentes do tempo de aquecimento, portanto podem ser consideradas sem importância para a prática culinária.

Conforme já mencionado, não foram encontrados estudos na literatura sobre a atividade antioxidante e/ou teor de compostos fenólicos de vinho tinto ou suco de uva após a fervura em preparações culinárias. No entanto, vale mencionar que o aquecimento dessas bebidas durante o processo de obtenção ou produção industrial é essencial para a estabilidade dos compostos fenólicos e da atividade antioxidante. De acordo com Malacrida \& Motta², as possíveis diferenças de processamento (tipo e tempo de extração, tratamento térmico, enzimático, dentre outros) entre as distintas marcas de vinho e de suco de uva comercializadas podem influenciar seu teor de compostos fenólicos. Além disso, o armazenamento e o processamento das uvas podem levar a mudanças deletérias em sua composição ${ }^{18}$. Em estudo realizado por Talcott et al. ${ }^{19}$, foi encontrado que no processo de pasteurização dos sucos de uva, aquecidos a $95^{\circ} \mathrm{C}$ por 15 minutos, ocorreu aumento da quantidade de fenóis totais e da atividade antioxidante nessas bebidas em relação à amostra controle (suco não pasteurizado). A justificativa desses autores é que a pasteurização degradou enzimas, como a polifenol oxidase, preservando, assim, a concentração de fenóis totais. Portanto, o aquecimento pode também preservar os fenóis totais presentes no suco de uva.

Com base no presente estudo e nos demais estudos citados, é possível recomendar a utilização do vinho tinto e do suco de uva em preparações culinárias submetidas à fervura, visando aos benefícios nutricionais dos compostos antioxidantes presentes nessas bebidas. Os compostos antioxidantes do vinho e da uva são importantes na prevenção, e possível tratamento, de doenças crônicas, como a aterosclerose, diabetes, hipertensão e, inclusive, certos tipos de cânceres ${ }^{3}$. Nesse sentido, pode-se recomendar o aumento da quantidade dessas bebidas em preparações culinárias, o que possivelmente elevará o consumo de compostos fenólicos.

Preparações que contêm vinho como ingrediente são reconhecidas pela culinária internacional. O vinho tinto costuma ser utilizado habitualmente por diferentes culturas, o que indica tratar-se de produto de fácil acesso pela população. Há, também, receitas da culinária regional brasileira, como o caso do sagu de vinho tinto, típico da culinária gaúcha ${ }^{10}$, ou sua variação preparada com suco de uva, que se tornam sobremesas interessantes do ponto de vista nutricional, por conterem antioxidantes.

\section{O N CLUS Ã O}

A capacidade antioxidante e os teores de compostos fenólicos do vinho tinto e do suco de uva permaneceram estáveis quando submetidos à fervura de até 60 minutos. Com isso, pode-se sugerir que o processo de cocção das preparações culinárias não influencia as propriedades nutricionais e os efeitos benéficos do vinho tinto e do suco de uva para a saúde humana, podendo ser explorado seu uso culinário.

Tendo em vista que, neste estudo, o vinho e o suco foram submetidos a processos térmicos, 
de forma isolada, verifica-se a necessidade de mais estudos nesta área, visando considerar as interações entre os compostos antioxidantes do vinho tinto e do suco de uva com os demais ingredientes das preparações, como no caso das carnes e dos temperos.

\section{COLABORADORES}

J.S.C. TEÓFILO e G.L. BERNARDO participaram da elaboração do projeto de pesquisa, coleta e análise dos dados, discussão dos resultados e elaboração do artigo. E.L. SILVA (professor colaborador) e R.P.C. PROENÇA (professora orientadora) participaram da elaboração do projeto de pesquisa, da análise dos dados, discussão dos resultados e elaboração do artigo.

\section{REFERÊ NCIAS}

1. Bellés VV. Presencia y actividad funcional de los polifenoles en alimentos y bebidas. In: Martinez $\mathrm{JR}$, Rosado $\mathrm{Cl}$, editores. Atualización en nutrición 2005: evidencias en nutrición. Madrid: Sanitária 2000; 2005.

2. Malacrida CR, Motta S. Compostos fenólicos totais e antocianinas em suco de uva. Ciênc Tecnol Aliment. 2005; 25(4):659-64. doi: 10.1590/S0101-20 612005000400006.

3. Chira K, Suh JH, Saucier C, Teissedre PL. Les polyphénols du raisin. Phytotherapie. 2008; 6(2): 75-82. doi: 10.1007/s10298-008-0293-3.

4. Auger C, Caporiccio B, Landrault N, Teissedre PL, Laurent C, Cros G, et al. Red wine phenolic compounds reduce plasma lipids and apolipoprotein B and prevent early aortic atherosclerosis in hypercholesterolemic golden syrian hamsters (Mesocricetus auratus). J Nutr. 2002; 132(6):1207-13.

5. Soares SE. Ácidos fenólicos como antioxidantes. Rev Nutr. 2002; 15(1):71-81. doi: 10.1590/S1415-52 732002000100008.

6. Flandrin J-L, Montanari M, editores. História da alimentação. São Paulo: Estação Liberdade; 1998.

7. Brillat-Savarin J-A. A fisiologia do gosto. São Paulo: Companhia das Letras; 1995.

8. Cascudo LC. História da alimentação no Brasil. São Paulo: Global; 2004.
9. Novakoski D, Freire R. Enogastronomia: a arte de harmonizar cardápios e vinhos. São Paulo: Senac; 2005.

10. Philippi ST. Nutrição e técnica dietética. Barueri: Manole; 2003.

11. Montebello NP. Condimentos, fundos e molhos. In: Araujo WMC, Montebello NP, Botelho RA, Borgo LAl, editores. Alquimia dos alimentos. Brasília: Senac; 2007.

12. Busquets R, Puignou L, Galceran MT, Skog K. Effect of red wine marinades on the formation of heterocyclic amines in fried chicken breast. J Agric Food Chem. 2006; 54(21):8376-84. doi: 10.1021/ jf0616311.

13. Melo A, Viegas O, Pestisca C, Pinho O, Ferreira IMPLVO. Effect of beer/red wine marinades on the formation of heterocyclic aromatic amines in panfried beef. J Agric Food Chem. 2008; 56(22): 10625-32. doi: 10.1021/jf801837s.

14. Benzie IFF, Strain JJ. The ferric reducing ability of plasma (FRAP) as a measure of antioxidant power: the FRAP assay. Anal Biochem. 1996; 239(1):70-6. doi: 10.1006/abio.1996.0292.

15. Tsao R, Yang R, Xie S, Sockovie E, Khanizadeh S. Which polyphenolic compounds contribute to the total antioxidant activities of apple? J Agric Food Chem. 2005; 53(12):4989-95. doi: 10.1021/jf04 $8289 \mathrm{~h}$

16. Singleton VL, Orthofer R, Lamuela-Raventos RM. Analysis of total phenols and other oxidation substrates and antioxidants by means of FolinCiocalteu reagent. Methods Enzymol. 1999; 299: 152-78. doi:10.1016/S0076-6879(99)99017-1.

17. Sokal RR, Rohlf FJ. Biometry: the principles and practice of statistics in biological research. $3^{\text {rd }}$ ed. New York: W.H. Freeman; 1995.

18. Del Pozo-Insfran D, Del Follo-Martinez A, Talcott ST, Brenes $\mathrm{CH}$. Stability of copigmented anthocyanins and ascorbic acid in muscadine grape juice processes by high hydrostatic pressure. J Food Sci. 2007; 72(4):s247-53. doi: 10.1111/j.1750-38 41.2007.00316.x.

19. Talcott ST, Brenes $C H$, Pires DM, Pozo-Insfran D. Phytochemical stability and color retention of copigmented and processed muscadine grape juice. J Agric Food Chem. 2003; 51(4): 957-63. doi: 10.1021/jf0209746.

Recebido em: 24/6/2009

Versão final reapresentada em: 6/12/2010 Aprovado em: 16/12/2010 
